\title{
Rapid one-step enzyme immunoassay and lateral flow immunochromatographic assay for colistin in animal feed and food
}

Jiayi Wang ${ }^{1}$, Jinyu Zhou', Yiqiang Chen ${ }^{1 *}$, Xinpei Zhang ${ }^{1}$, Yongpeng Jin ${ }^{1}$, Xiaojing Cui ${ }^{1}$, Dongting He', Wenqing Lai ${ }^{1}$ and Lidong $\mathrm{He}^{2}$

\begin{abstract}
Background: Colistin (polymyxin E) is a kind of peptide antibiotic which has been approved in animal production for the purposes of disease prevention, treatment, and growth promotion. However, the wide use of colistin in animal feed may accelerate the spread of colistin-resistance gene MCR-1 from animal production to human beings, and its residue in animal-origin food may also pose serious health hazards to humans. Thus, it is necessary to develop corresponding analytical methods to monitor the addition of colistin in animal feed and the colistin residue in animal-origin food.
\end{abstract}

Results: A one-step enzyme-linked immunosorbent assay (ELISA) and a lateral flow immunochromatographic assay (LFIA) for colistin were developed based on a newly developed monoclonal antibody. The ELISA showed a 50\% inhibition value $\left(\mathrm{IC}_{50}\right)$ of $9.7 \mathrm{ng} / \mathrm{mL}$ with assay time less than $60 \mathrm{~min}$, while the LFIA had a strip reader-based detection limit of $0.87 \mathrm{ng} / \mathrm{mL}$ in phosphate buffer with assay time less than $15 \mathrm{~min}$. For reducing the non-specific adsorption of colistin onto sample vial, the components of sample extraction solution were optimized and proved to greatly improve the assay accuracy. The spiked recovery experiment showed that the recoveries of colistin from feed, milk and meat samples were in the range of $77.83 \%$ to $113.38 \%$ with coefficient of variations less than $13 \%$ by ELISA analysis and less than $18 \%$ by LFIA analysis, respectively. Furthermore, actual sample analysis indicated that the two immunoassays can produce results consistent with instrumental analysis.

Conclusions: The developed assays can be used for rapid qualitative or quantitative detection of colistin in animal feed and food.

Keywords: Colistin, ELISA, Feed, Food, Gold nanoparticle, Lateral flow immunochromatographic assay, Monoclonal antibody

\section{Background}

Colistin (polymyxin E) is a kind of peptide antibiotic which is produced by Bacillus polymyxa subsp. it is generally a mixture that can be divided into colistin $\mathrm{A}$ (polymyxin $\mathrm{E}_{1}$ ) and colistin $\mathrm{B}$ (polymyxin $\mathrm{E}_{2}$ ) depending on the fatty acid side chain. In human clinic, colistin is used to treat infections from multidrug-resistant Gram-negative bacteria such as Enterobacteriaceae and Pseudomonas aeruginosa. Because it is considered one of the last-resort antibiotics for

\footnotetext{
* Correspondence: yqchen@cau.edu.cn

${ }^{1}$ Beijing Advanced Innovation Center for Food Nutrition and Human Health, and State Key Laboratory of Animal Nutrition, College of Animal Science and Technology, China Agricultural University, Beijing, China

Full list of author information is available at the end of the article
}

these infections [1], the World Health Organization [2] has classified it in the category of critically important antimicrobials. In the meantime, colistin has been approved to be used in animal production for the purposes of disease prevention, treatment, and growth promotion [3]. However, after the use of colistin in animal production for decades, a significant resistance of Enterobacteriaceae to colistin in livestock has been reported by several research groups [46]. More recently, Shen and his colleagues identified the first mobile colistin-resistance gene named MCR-1 in Escherichia coli which was isolated from food-producing animals [7], and this gene was subsequently reported in more than 30 countries [8]. These studies suggested that

(c) The Author(s). 2019 Open Access This article is distributed under the terms of the Creative Commons Attribution 4.0 International License (http://creativecommons.org/licenses/by/4.0/), which permits unrestricted use, distribution, and reproduction in any medium, provided you give appropriate credit to the original author(s) and the source, provide a link to the Creative Commons license, and indicate if changes were made. The Creative Commons Public Domain Dedication waiver (http://creativecommons.org/publicdomain/zero/1.0/) applies to the data made available in this article, unless otherwise stated. 
addition of colistin in animal diet has accelerated the spread of MCR-1 from animal production to human beings [9]. After extensive risk assessment, the Chinese Ministry of Agriculture released an announcement (No. 2428) to ban the use of colistin as a feed additive to animals since April of 2017 [10]. Moreover, colistin as a veterinary pharmaceutical remains legal use to treat intestinal infections in animals and cow mastitis. Nevertheless, the intramuscular or intramammary administration of colistin may lead to colistin residue in edible food such as milk and meat, and subsequently pose potential nephrotoxicity and neurotoxicity to human. Meantime, the low level of colistin in animal-origin food may also induce resistant bacteria as the predicted no effect concentrations of colistin for resistance selection is only $2 \mathrm{ng} / \mathrm{mL}$ [11]. To maintain consumer health, the maximum residue limits (MRLs) of colistin in edible food such as milk and meat have been set at 50 and $150 \mu \mathrm{g} / \mathrm{kg}$ respectively by the Codex Alimentarius FAOWHO [12]. Therefore, it is necessary and important to monitor the illegal addition of colistin in animal feed and the colistin residue in animal-origin food for combating bacteria drug-resistance and ensuring public health.

Analytical methods for colistin measurement include microbiological assay [13, 14], enzyme immunoassay [15], high performance liquid chromatography (HPLC) [16-19], and liquid chromatography coupled with tandem mass spectrometry (LC-MS/MS) [20-24]. Microbiological assay is relatively labor-insensitive and time-consuming compared to these methods $[15,25]$ and is now rarely used for colistin detection. HPLC analysis requires complex sample pretreatment such as protein precipitation and solid phase extraction. Moreover, as colistin has no strong ultraviolet (UV)-absorption and fluorescence, it has to be derivatised with 9-fluorenylmethyl chloroformate (FMOC-Cl) [16, 19] or ortho-phthalaldehyde (OPA) $[17,18]$ before UV or fluorescence detection. LC-MS/MS has been widely used for the determination of colistin in different matrixes owing to its high sensitivity and high selectivity, but it requires even more extensive sample pretreatment and is more susceptible to sample matrixes than LC analysis [23, 24]. Therefore, these two types of instrumental analysis are not advisable for rapid screening of bulk samples. As a comparison, immunoassay such as ELISA and LFIA has the advantages of high assay sensitivity, high throughput and rapid turnaround time, making them more suitable for rapid monitoring of colistin [26]. Previously, Kitagawa et al. [25] reported an enzyme immunoassay for colistin in rainbow trout tissue, but the assay sensitivity was too low to be practically used. Suhren and Knappstein [15] developed an ELISA approach for colistin in milk, but polyclonal antibodies were employed in the study, the titers and affinities of each batch of sera would be different. Moreover, the accuracy and precision of this assay was not good enough for quantitative analysis [15]. Therefore, in this study, we prepared a new monoclonal antibody against colistin and developed a rapid one-step ELISA for colistin in animal feed and food. As compared to ELISA, LFIA is a more rapid, simpler and more economic approach and is suitable for the detection of colistin in field environment. Currently, there is no research report about LFIA for colistin in biological matrixes. Thus, based on the prepared $\mathrm{mAb}$, we also developed a LFIA as an alternative to ELISA for on-site detection of colistin. In addition, one obstacle for accurate determination of colistin in biological matrixes relies on its non-specific adsorption on container surface, which has been extensively reported in the development of instrumental analysis [23, 27]. Internal standard such as polymyxin B was generally employed to counteract the negative effect of non-specific adsorption [23, 28]. However, the use of polymyxin B as internal standard is not appropriate in immunoassay since the molecular structures between polymyxin B and colistin are quite similar and the antibody against colistin would also recognize polymyxin $B$. Thus, in this study, we investigated the extent of non-specific adsorption on different sample vials and optimized the extraction solution, aiming to reduce non-specific adsorption of colistin and improve the assay accuracy and precision.

\section{Methods}

\section{Chemicals and apparatus}

Colistin sulfate, kanamycin sulfate, neomycin sulfate, streptomycin sulfate, gentamicin sulfate, 1-ethyl-3-(3dimethylaminopropyl) carbodiimide (EDC), chlorauric acid, bovine serum albumin (BSA), ovalbumin (OVA), Freund's complete adjuvant, Freund's incomplete adjuvant, goat anti-mouse IgG and goat anti-mouse IgGhorseradish peroxidase (HRP) conjugate were bought from Sigma-Aldrich (St. Louis, MO, USA). RPMI 1640 medium, fetal bovine serum (FBS), polyethylene glycol 1500 (PEG 1500), hypoxanthine-aminopterin-thymidine (HAT) medium, and hypoxanthine-thymidine (HT) medium were supplied by Gibco BRL (Rockville, MD, USA). Other reagents were provided by Beijing Regent Corporation (Beijing, China).

Swine feed and chicken feed used as blank matrixes are obtained from Da Bei Nong Group (Beijing, China) and New Hope Liuhe Group (Beijing, China). Nitrocellulose membrane $\mathrm{CN} 140$ was bought from Whatman International Ltd. (Middlesex, UK). Absorbent pad $\mathrm{CH}$ 37, adhesive backing card and sample pad (GF2-II) were provided by Shanghai GoldBio Co. Ltd. (Shanghai, China). Microtiter plates, cell culture bottles, microculture plates, were bought from Costar Group Inc. (Bethesda, MD, USA). HM 3030 Dispensing Platform and ZQ 2000 Guillotine Cutting Module (Shanghai GoldBio Co. Ltd., Shanghai, China) were used for the assembly of LFIA strips. 


\section{Preparation of immunogen and coating antigen}

The conjugates colistin-BSA and colistin-OVA were synthesized by carbodiimide coupling method according to the procedure as below. Briefly, $10 \mathrm{mg}$ of carrier protein (BSA or OVA) was dissolved in $2 \mathrm{~mL}$ of $0.05 \mathrm{~mol} / \mathrm{L}$ MES buffer ( $\mathrm{pH} 6.0,0.5 \mathrm{~mol} / \mathrm{L} \mathrm{NaCl}$ ) and then $0.5 \mathrm{~mL}$ of 40 $\mathrm{mg} / \mathrm{mL}$ EDC was added dropwise. After reaction at room temperature for $2 \mathrm{~h}$, the colistin-protein conjugates were dialyzed against phosphate buffer saline (PBS) at $4{ }^{\circ} \mathrm{C}$ for 2 days and were then characterized by MALDITOF mass spectrometry (Bruker Daltonics, Germany). The colistin-BSA conjugate was used as immunogen and the colistin-OVA conjugate was used as coating antigen.

\section{Preparation of monoclonal antibody (mAb) Immunization}

The procedures used throughout this experiment were approved by the China Agricultural University Institutional Animal Care and Use Committee (CAll201609251, Beijing, China). Twenty 8 weeks old female BALB/c mice were divided into two groups (10 mice each) and immunized with colistin-BSA conjugate. The mice in the two groups were respectively immunized with $15 \mu \mathrm{g}$ or $60 \mu \mathrm{g}$ of the immunogen per mouse by subcutaneously injecting the emulsion of colistin-BSA and Freund's complete adjuvant. Then three booster immunizations were performed at every 4 weeks and the immunization dosage was the same but the immunogen was emulsified in Freund's incomplete adjuvant. Seven days after each immunization, the antisera were collected and evaluated for anti-colistin activity by competitive indirect ELISA (ciELISA). The mouse producing antiserum with the highest affinity to colistin received another immunization intraperitoneally, and 4 days later, the mouse was sacrificed for cell fusion and hybridoma production.

\section{Cell fusion and hybridoma production}

Cell fusion was performed according to the following procedure [29]. Briefly, the spleen lymphocytes of the sacrificed mouse was fused with myeloma cells at a ratio of 5:1 using PEG 1500 as fusing reagent. The fused cells were then suspended in HAT-RPMI 1640 medium containing $20 \%$ fetal calf serum and $10 \mu \mathrm{g} / \mathrm{mL}$ gentamicin and streptomycin, and were then allocated to ten 96-well microculture plates. Twelve days following the fusion, the supernatants of each well were tested by both noncompetitive and competitive indirect ELISA. The cells in micro-culture wells indicating a significant colistin recognition activity were further cloned by limiting dilution using HT-RPMI 1640 medium containing 20\% fetal calf serum. The cell clones that can stably produce antibodies were then large-scale cultured and finally cryopreserved in liquid nitrogen.

\section{Production and purification of monoclonal antibody ( $m A b$ )}

Mature female BALB/c mouse was intraperitoneally injected with $0.5 \mathrm{~mL}$ of paraffin. Eight days later, the antibody-producing hybridoma cells was intraperitoneally injected. After 11 days, ascites fluid can be collected and the purification of $\mathrm{mAb}$ was performed by saturated ammonium sulfate method followed by passing through Hitrap protein A HP antibody purification column (GE Healthcare Life Sciences, USA). The isotypes of the purified mAbs were determined by a rapid mouse antibody isotyping ELISA kit (Thermo Scientific, West Palm Beach, USA).

\section{One-step competitive indirect ELISA}

The assay procedures of one-step ci-ELISA (Fig. 1a) were as follows: Firstly, $100 \mu \mathrm{L}$ of colistin-OVA conjugate $(1.0 \mu \mathrm{g} / \mathrm{mL})$ was coated on each polystyrene plate

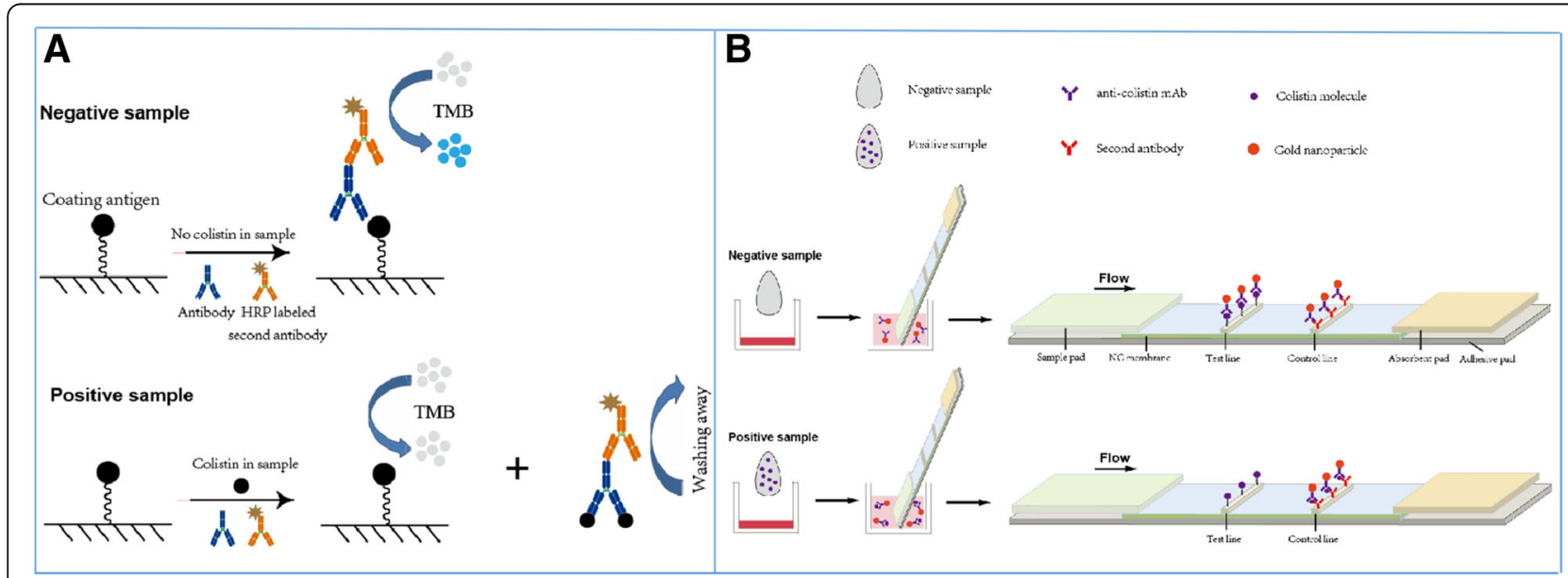

Fig. 1 Schemes of one-step competitive indirect ELISA (a) and lateral flow immunochromatographic assay (b) for colistin 
well. After incubation at $37^{\circ} \mathrm{C}$ for $2 \mathrm{~h}$, the solution in wells was discarded and the plates were then washed three times with $0.01 \mathrm{~mol} / \mathrm{L}$ PBS containing $0.05 \%$ Tween 20 (PBST). Afterwards, $50 \mu \mathrm{L}$ of analyte was added followed by the addition of a mixture (1:1) of anti-colistin $\mathrm{mAb}$ solution (1:2000 in $0.01 \mathrm{~mol} / \mathrm{L} \mathrm{PBS})$ and HRP labeled goat anti-mouse $\operatorname{IgG}$ (1:3000 in 0.01 $\mathrm{mol} / \mathrm{L} \mathrm{PBS})$. After incubation at $37^{\circ} \mathrm{C}$ for $45 \mathrm{~min}$, the plate wells were repeatedly washed with $\mathrm{PBST}$ for three times. Then $100 \mu \mathrm{L}$ of the $\mathrm{TMB} / \mathrm{H}_{2} \mathrm{O}_{2}$ substrate/ chromogen solution ( $\mathrm{pH}$ 5.5) was added into each well and was incubated at $37^{\circ} \mathrm{C}$ for $10 \mathrm{~min}$. Subsequently, the enzymatic reaction was terminated by adding $50 \mu \mathrm{L} /$ well of $2 \mathrm{~N} \mathrm{H}_{2} \mathrm{SO}_{4}$. Finally, the optical density (OD) was determined at $450 \mathrm{~nm}$ by a Synergy ${ }^{\text {ni }}$ H4 Hybrid Microplate Reader (BioTek Instruments Inc., USA). A calibration curve was established by plotting relative absorbance $\left(\mathrm{B} / \mathrm{B}_{0}\right)$ against the logarithm of colistin concentration and it was then fitted to a four-parameter logistic equation. The $\mathrm{IC}_{50}$ value was obtained from the equation and it was used for the evaluation of ELISA sensitivity. The cross-reactivity of several common antimicrobials drugs such as bacitracin, aminoglycosides, $\beta$-lactams, tetracyclines, sulfonamides, and quinolones to the colistin ELISA were measured and the cross-reactivity values were calculated according to the following equation: percent cross-reactivity $=\left(\mathrm{IC}_{50}\right.$ of colistin / $\mathrm{IC}_{50}$ of analytes $\times 100 \%$ ).

\section{LFIA development}

\section{Preparation of gold nanoparticle (GNP)}

Different sizes of GNPs were prepared according to the following procedures [30]. One hundred milliliter of chlorauric acid solution $(0.01 \%, w / v)$ was prepared and then heated to boiling. Subsequently, 2.5, 2.0, 1.6 or 1 $\mathrm{mL}$ of $1 \%(w / v)$ sodium citrate solution were added to react with chlorauric acid for 15 min under boiling and stirring conditions. Then the solution was cooled down and deionized water was supplemented to the original volume. Finally, the synthesized GNPs were scanned by ultraviolet (UV) spectrophotometer, and the particle sizes of GNPs were measured by transmission electron microscopy (TEM, JEOL Inc., MA, USA).

\section{Preparation of detection reagent}

The detection reagent was prepared by conjugating anticolistin $\mathrm{mAb}$ onto the surface of GNPs. Under mild stirring condition, the $\mathrm{pH}$ value of gold nanoparticle (10 $\mathrm{mL}$ ) was adjusted to 8.0 with $0.1 \mathrm{~mol} / \mathrm{L} \mathrm{K}_{2} \mathrm{CO}_{3}$ solution, then $30 \mu \mathrm{g}$ of the purified anti-colistin mAb was dropwise added. Following incubation at room temperature for $20 \mathrm{~min}, 1 \mathrm{~mL}$ of $1 \%$ BSA solution was added and the mixed solution was then incubated for $15 \mathrm{~min}$. Subsequently, the prepared Ab-GNP conjugate was centrifuged at $8000 \mathrm{r} / \mathrm{min}$ for $15 \mathrm{~min}$, the supernatant was discarded and the precipitate was re-suspended in $10 \mathrm{~mL}$ of $0.01 \mathrm{~mol} / \mathrm{L}$ PBS containing $1 \%$ sucrose, $1 \%$ BSA and $0.5 \%$ Triton X-100 (pH 7.4). Finally, $50 \mu \mathrm{L}$ of the Ab-GNP conjugate solution was added into each microplate well and was then freeze-dried for use.

\section{Immobilization of capture reagent and control reagent}

For this LFIA, nitrocellulose membrane with width of $4 \mathrm{~cm}$ was used. The goat anti-mouse IgG $(0.4 \mathrm{mg} / \mathrm{mL})$ and colistin-OVA $(0.25 \mathrm{mg} / \mathrm{mL})$ were dispensed onto the nitrocellulose membrane as the control line and test line, respectively, with dispensing volume of $1 \mu \mathrm{L} /$ $\mathrm{cm}$ line. Then the dispensed nitrocellulose membrane was dried at $37^{\circ} \mathrm{C}$ for $6 \mathrm{~h}$ and stored under dry conditions until use.

\section{Strip assembly}

The LFIA strip includes four parts: nitrocellulose membrane, sample pad, absorbent pad, and adhesive backing card (Fig. 1b). The strip assembly was described as below: Briefly, the nitrocellulose membrane lined with capture antigens and control reagent was pasted on the middle of adhesive backing card, then the sample pad and the absorbent pad were pasted on the two ends of adhesive backing card and overlapped the nitrocellulose membrane by $2 \mathrm{~mm}$. Lastly, the assembled plate was cut to strips with width of $4 \mathrm{~mm}$.

\section{Test procedure}

Briefly, $200 \mu \mathrm{L}$ of sample solution was added into the micro-plate well containing detection reagent. After dissolving the detection reagent and incubating for 3 min, the sample pad end of test strip was immersed into the well, and then the solution would flow toward the absorbent pad. After $10 \mathrm{~min}$, the test result can be visually judged, and the line intensities can be measured by a strip reader (NB Gene Ltd., Beijing, China).

\section{Sample preparation and analysis}

The sample preparation procedures are described as below which referred to the procedures from literature report $[15,24]$. For animal feed sample, $1.0 \mathrm{~g}$ of the sample was weighed and added with $100 \mathrm{~mL}$ of $2 \%$ trichloroacetic acid aqueous solution (TCA) containing $1 \%$ Triton X-100. Then the mixed solution was continually stirred for $30 \mathrm{~min}$ and was subsequently filtered to obtain the supernatant. The $\mathrm{pH}$ value of the extract was adjusted to neutral and the solution was ready for ELISA or LFIA analysis. For milk sample, $1.0 \mathrm{~g}$ of the sample was mixed with $4 \mathrm{~mL}$ of $2 \%$ TCA aqueous solution containing 1\% Triton X-100 and was then vortexed for 5 min. Subsequently, the mixed solution was filtered and the solution $\mathrm{pH}$ value was adjusted to neutral. Finally, the neutralized solution was applied to ELISA or LFIA 
analysis. For pork meat sample, $1.0 \mathrm{~g}$ of the sample was weighed and mixed with $20 \mathrm{~mL}$ of $4 \%$ TCA aqueous solution containing 1\% Triton X-100). The mixed solution was ultrasonic-assisted extracted for $20 \mathrm{~min}$ and was then filtered to obtain the supernatant. After the solution was neutralized with sodium hydroxide, it was then subjected to ELISA or LFIA analysis. For spiked experiment, colistin standard solution was added into blank samples and the spiked concentrations were $0.5-4.0 \mathrm{mg} /$ $\mathrm{kg}$ for swine feed and chicken feed samples, 25-100 $\mu \mathrm{g} /$ $\mathrm{kg}$ for milk samples and $75-300 \mu \mathrm{g} / \mathrm{kg}$ for meat samples, respectively. Four different blank samples for each type of sample matrix were used in the spiked experiment. The spiked samples and the blank samples were then pretreated and analyzed by the developed ELSA and LFIA. Three repeats were performed for each sample. For real sample analysis, 20 samples were simultaneously measured by the developed immunoassays and LC-MS/ MS method [24] and their analytical results were compared.

\section{Results and discussion}

\section{Antibody preparation and characterization}

Colistin is a small molecule which cannot elicit animal body to produce a specific antibody, thus it was covalently linked with BSA by EDC coupling method to form an immunogen for antibody preparation. By MALDI-TOF analysis, the conjugation ratio of colistin to BSA is about 6.9:1 (Fig. 2), which was considered to be suitable for antigen immunization and antibody production [31]. The antibody titer and affinity of sera from mice was then monitored since the third immunization. The result indicated that the titers and $\mathrm{IC}_{50}$ values of all sera remained roughly the same between the third and the fourth immunization, therefore, after the fifth immunization, the final bleeding was performed. For investigating the effect of immunization dosage on antibody affinity, two dosage groups $(15 \mu \mathrm{g}$ and $60 \mu \mathrm{g}$ per immunization) were performed in this study. The low dosage group led to $\mathrm{IC}_{50}$ values in the range of 68 to $133 \mathrm{ng} / \mathrm{mL}$, while the high dosage group resulted in $\mathrm{IC}_{50}$ values of 76 to $149 \mathrm{ng} / \mathrm{mL}$ (Additional file 1: Table S1), indicating that the two immunization dosages did not produce significant difference on the affinities of sera antibodies. The mouse from low-dosage group produced the serum with the lowest $\mathrm{IC}_{50}$ value of $68 \mathrm{ng} / \mathrm{mL}$, and it was then sacrificed for hybridoma preparation. After cell fusion and cloning, four hybridomas excreting anti-colistin antibodies were obtained. The hybridoma named 3D5-E7 was chosen for antibody production because it can excrete $\mathrm{mAb}$ with the lowest $\mathrm{IC}_{50}$ value of $10.1 \mathrm{ng} /$ $\mathrm{mL}$. This means that as compared to the mouse antiserum, the affinity of this mAb increased by about 7 times, thus the mAb from the hybridoma 3D5-E7 was

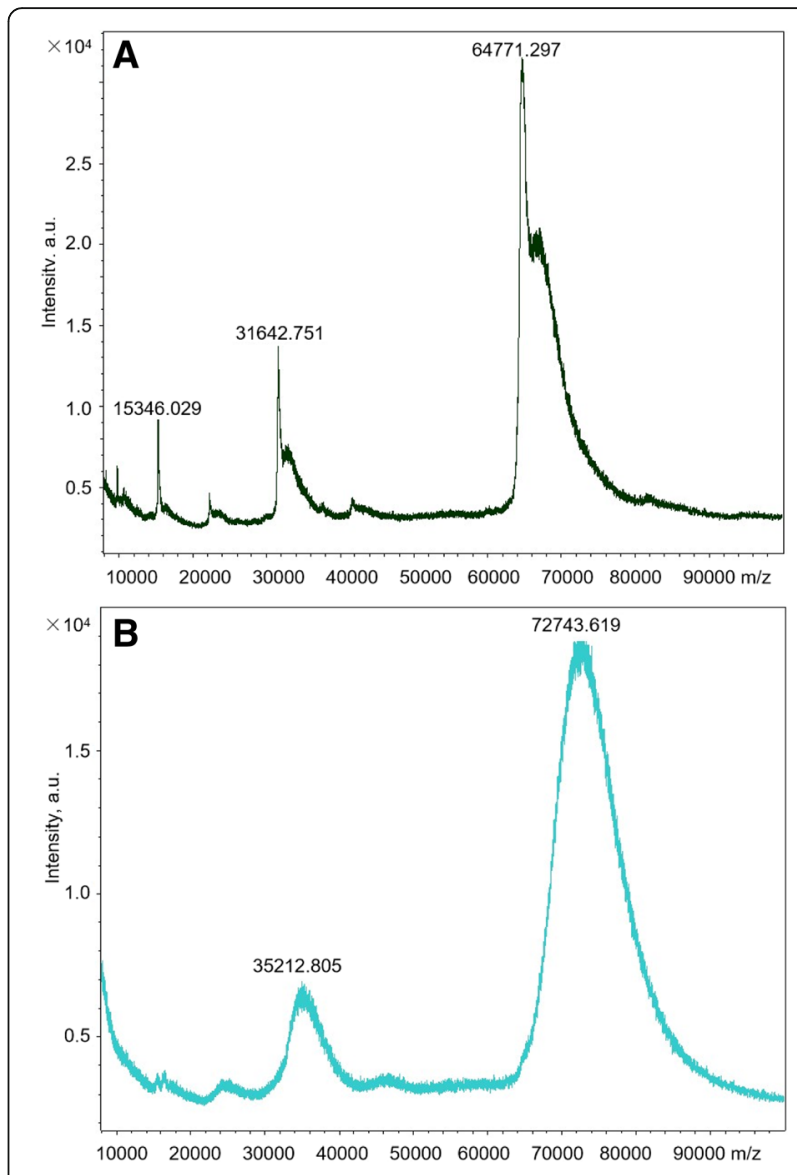

Fig. 2 MALDI-TOF analysis of BSA (a) and colistin-BSA conjugate (b)

further evaluated for antibody specificity and was used for subsequent immunoassay development. The isotype of this mAb was determined to be IgG 2a. Several common antimicrobial drugs such as bacitracin, aminoglycosides, $\beta$-lactams, tetracyclines, sulfonamides, quinolones, and chloramphenicol were tested for antibody specificity. The result showed that this mAb can specifically recognized colistin and it had negligible cross-reactivity with other antimicrobial drugs as mentioned above (Table 1).

\section{ELISA optimization}

Conventional ELISA generally employs competitive direct ELISA (cd-ELISA) or ci-ELISA format (Additional file 1: Figure S1). The cd-ELISA only needs one-step immunological reaction, but it requires the preparation of hapten-enzyme conjugate. The ci-ELISA format employs commercially available second antibody-enzyme conjugate, but it normally requires two-step immunological reaction. In this study, we introduced a one-step ciELISA and compared this assay format with cd-ELISA and two-step ci-ELISA regarding assay sensitivity and assay time (Additional file 1: Table S2). After the optimization of $\mathrm{pH}$ value, ionic strength, coating 
Table 1 Cross-reactivity of anti-colistin mAb with other common antibacterial drugs

\begin{tabular}{lll}
\hline Analyte & $\mathrm{IC}_{50}, \mathrm{ng} / \mathrm{mL}$ & $\begin{array}{l}\text { Cross } \\
\text {-reactivity, } \\
\%\end{array}$ \\
\hline Colistin & 10.1 & 100 \\
Bacitracin & $>2000$ & $<0.1$ \\
Neomycin & $>2000$ & $<0.1$ \\
Penicillin G & $>2000$ & $<0.1$ \\
Tetracycline & $>2000$ & $<0.1$ \\
Sulfadimidine & $>2000$ & $<0.1$ \\
Enrofloxacin & $>2000$ & $<0.1$ \\
Chloramphenicol & $>2000$ & $<0.1$ \\
\hline
\end{tabular}

condition, and incubation time for each step, the assay performance of the three assay formats was shown in Fig. 3. The result indicated that the assay sensitivities of one-step ci-ELISA $\left(\mathrm{IC}_{50}=9.7 \mathrm{ng} / \mathrm{mL}\right)$ and two-step ciELISA $\left(\mathrm{IC}_{50}=9.1 \mathrm{ng} / \mathrm{mL}\right)$ were comparable, and both of them are superior to cd-ELISA $\left(\mathrm{IC}_{50}=23.7 \mathrm{ng} / \mathrm{mL}\right)$. As the assay time of one-step ci-ELISA $(\sim 60 \mathrm{~min})$ was much less than two-step ci-ELISA $(\sim 110 \mathrm{~min})$, the newly developed one-step ci-ELISA was selected to perform in the subsequent experiment.

\section{Optimization of LFIA}

\section{The effect of gold nanoparticle}

To study the effect of GNP size on LFIA sensitivity, four sizes of GNPs were synthesized [30]. The UV-vis spectra of the four GNPs solutions synthesized by reducing chlorauric acid with 1.0, 1.6, 2.0 and $2.5 \mathrm{~mL}$ of citrate solution showed maximum absorption peaks at 530, 526, 522 and $519 \mathrm{~nm}$, respectively (Additional file 1: Figure S2). Transmission electron microscope (TEM) images of the four GNPs are shown in Additional file 1: Figure S3

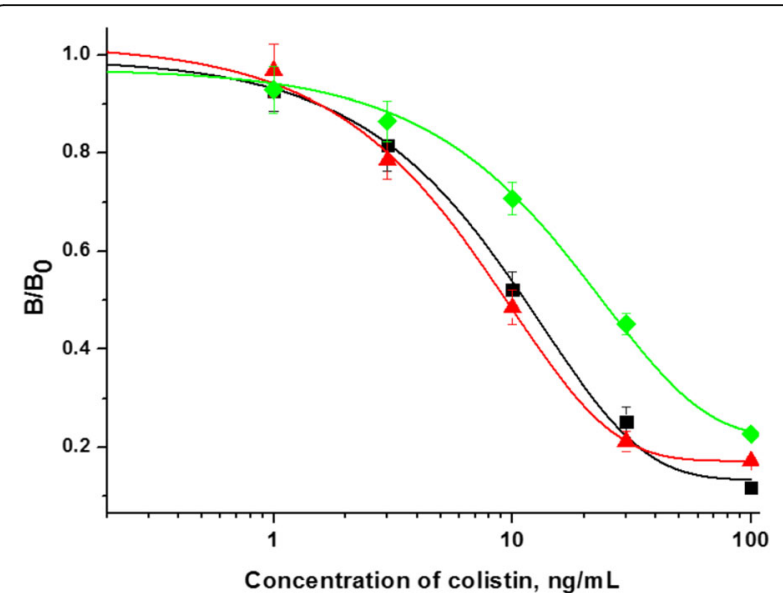

Fig. 3 Calibration curves of three types of ELISA for colistin $(n=4)$ : ( $\mathbf{\bullet})$ One-step ci-ELISA; $(\boldsymbol{\Delta})$ Two-step ci-ELISA; $\bullet$ cd-ELISA and their sizes were measured to be 36, 25, 16 and 12 $\mathrm{nm}$, respectively. Literature reports indicated that larger size of GNPs can produce higher assay sensitivity than smaller GNPs [32, 33]. In our study, $36 \mathrm{~nm}$ GNPs also result in slightly higher sensitivity than other sizes of GNPs. However, it was found that the Ab-GNPs conjugate with $36 \mathrm{~nm}$ GNPs was not stable and tended to aggregation during sample preparation process, which may be attributed to the high salt concentration in sample extracts. In contrast, the Ab-GNP conjugate prepared with smaller GNPs was much more stable. Therefore, we finally chose $25 \mathrm{~nm}$ of GNPs for the LFIA development.

\section{Optimizing $\mathrm{pH}$ value and antibody amount for Ab-GNP preparation}

Antibodies can physically conjugate on the surface of GNPs by electrostatic interaction. The $\mathrm{pH}$ value and antibody amount for Ab-GNP preparation would influence the antibody orientation and density on GNP [33], and thus both parameters may be related to the affinity of Ab-GNP conjugate and affect the LFIA sensitivity. Hence a checkerboard test was performed to select the appropriate $\mathrm{pH}$ value and the antibody amount for the preparation of Ab-GNP. The result indicated that the increase of antibody amount for Ab-GNP preparation produces stronger test line intensity, while the strength of test line intensity becomes weaker with the increase of $\mathrm{pH}$ value. At similar line intensity, the optimal combination of $\mathrm{pH}$ value and antibody amount that led to the most significant difference between negative and positive samples were determined to be $\mathrm{pH} 8.0$ and $3.0 \mu \mathrm{g}$ of anti-colistin mAb, respectively.

\section{Reduction of non-specific adsorption}

The non-specific adsorption of colistin on vials is one major problem for colistin analysis, which could result in the low recovery of colistin from samples. In order to reduce the effect of non-specific adsorption, most instrumental analysis employed polymyxin B as internal standard [23, 27]. Because polymyxin B antibiotic is an analogue of colistin which can also be recognized by anti-colistin $\mathrm{mAb}$, it cannot be used to verify the assay accuracy of colistin immunoassays. To address the non-specific adsorption problem, we firstly tested the adsorption ratios of colistin on different vials with different materials including Eppendorf vial, low-adsorption Eppendorf vial, and glass vial. Unfortunately, colistin can absorb on all the tested vials (Fig. 4a). Then we tried several polymers including polyvinyl pyrrolidone (PVP), polyethylene glycol (PEG), and polyvinyl alcohol (PVA) to block the non-specific adsorption sites on vials. Although the non-specific adsorption of colistin can be partly reduced by these polymers, the nonspecific problem was still significant. (Fig. 4b). Literature has reported the use of BSA to reduce colistin adsorption 


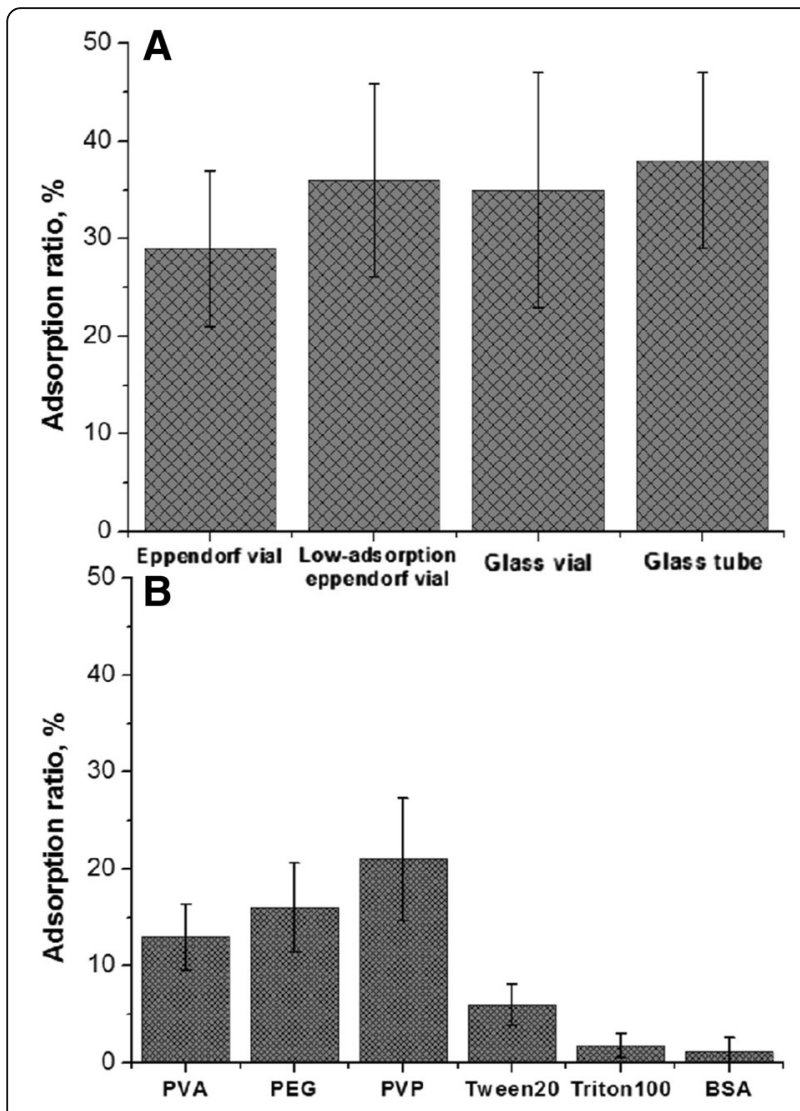

Fig. 4 Adsorption ratio of colistin in different vials (a) and after blocking with different reagents $(\mathbf{b})$

in urine sample [23], and we also confirmed that the addition of BSA in standard colistin solution could effectively reduce the non-specific adsorption (Fig. 4b). However, our further experiment found that colistin can also produce non-specific adsorption in acid sample extraction solution (2\% TCA). At acid condition, BSA would be denatured and form precipitate after centrifugation during sample pretreatment process, and hence it cannot be used in acid extraction solution. As an alternative, we then tested the surfactants including Tween 20 and Triton X-100 for blocking the non-specific adsorption (Fig. 4b). As a result, Triton X-100 presented a good effect on reducing non-specific adsorption, and the concentration of $1 \%$ presented the best effect, thus we chose $1 \%$ Triton X-100 to be used as a blocking reagent which was added into the sample extraction solution and standard colistin solution to eliminate the non-specific adsorption.

\section{Method validation}

One-step ci-ELISA

The limits of detection (LOD) are defined as $3.3 \sigma / S$, where $\sigma$ is the standard deviation of background signal from blank samples, and S is the slope of calibration curve [34]. By calculation, the LOD of the one-step ELISA were measured to be $101.4 \mu \mathrm{g} / \mathrm{kg}$ for swine feed sample, $103.2 \mu \mathrm{g} / \mathrm{kg}$ for chicken feed sample, $5.4 \mu \mathrm{g} / \mathrm{kg}$ for milk sample and $24.6 \mu \mathrm{g} /$ $\mathrm{kg}$ for meat samples $(n=20)$, respectively. At the spiked colistin concentrations of $1.0-4.0 \mathrm{mg} / \mathrm{kg}$ in swine feed and chicken feed, $25-100 \mu \mathrm{g} / \mathrm{kg}$ in milk sample, and $75-300 \mu \mathrm{g} /$

Table 2 Spiked recoveries and coefficient of variations (CVs) of one-step ci-ELISA and LFIA for colistin in animal feed and food $(n=4)$

\begin{tabular}{|c|c|c|c|c|c|}
\hline Method & $\begin{array}{l}\text { Sample } \\
\text { type }\end{array}$ & $\begin{array}{l}\text { Spiked } \\
\text { concentration }\end{array}$ & $\begin{array}{l}\text { Measured } \\
\text { concentration }\end{array}$ & $\begin{array}{l}\text { Recovery, } \\
\%\end{array}$ & $\begin{array}{l}\mathrm{CV}, \\
\%\end{array}$ \\
\hline \multirow{16}{*}{$\begin{array}{l}\text { One- } \\
\text { step } \\
\text { ELISA }\end{array}$} & $\begin{array}{l}\text { Swine feed, } \\
\mathrm{mg} / \mathrm{kg}\end{array}$ & 0 & $<\mathrm{LOD}$ & - & - \\
\hline & & 1.0 & $0.93 \pm 0.11$ & 93.20 & 11.40 \\
\hline & & 2.0 & $1.86 \pm 0.18$ & 93.03 & 9.53 \\
\hline & & 4.0 & $3.27 \pm 0.08$ & 81.63 & 2.48 \\
\hline & $\begin{array}{l}\text { Chicken } \\
\text { feed, mg/ } \\
\text { kg }\end{array}$ & 0 & $<\mathrm{LOD}$ & - & - \\
\hline & & 1.0 & $1.08 \pm 0.09$ & 108.00 & 8.33 \\
\hline & & 2.0 & $1.93 \pm 0.14$ & 96.57 & 7.30 \\
\hline & & 4.0 & $3.89 \pm 0.18$ & 97.34 & 4.56 \\
\hline & Milk, $\mu \mathrm{g} / \mathrm{kg}$ & 0 & $<L O D$ & - & - \\
\hline & & 25 & $27.53 \pm 2.97$ & 110.13 & 10.78 \\
\hline & & 50 & $49.87 \pm 3.41$ & 99.74 & 6.83 \\
\hline & & 100 & $87.44 \pm 7.79$ & 87.44 & 8.91 \\
\hline & Meat, $\mu \mathrm{g} /$ & 0 & $<\mathrm{LOD}$ & - & - \\
\hline & & 75 & $73.14 \pm 8.89$ & 97.52 & 12.16 \\
\hline & & 150 & $116.75 \pm 13.13$ & 77.83 & 11.25 \\
\hline & & 300 & $253.17 \pm 24.79$ & 84.39 & 9.79 \\
\hline \multirow[t]{16}{*}{ LFIA } & $\begin{array}{l}\text { Swine feed, } \\
\mathrm{mg} / \mathrm{kg}\end{array}$ & 0 & $<\mathrm{LOD}$ & - & - \\
\hline & & 0.5 & $0.44 \pm 0.07$ & 87.86 & 16.75 \\
\hline & & 1.0 & $1.14 \pm 0.16$ & 114.45 & 13.94 \\
\hline & & 2.0 & $1.74 \pm 0.15$ & 87.23 & 8.57 \\
\hline & $\begin{array}{l}\text { Chicken } \\
\text { feed, mg/ } \\
\mathrm{kg}\end{array}$ & 0 & $<\mathrm{LOD}$ & - & - \\
\hline & & 0.5 & $0.56 \pm 0.05$ & 112.84 & 9.04 \\
\hline & & 1.0 & $0.95 \pm 0.13$ & 95.43 & 13.57 \\
\hline & & 2.0 & $1.92 \pm 0.12$ & 95.85 & 6.03 \\
\hline & Milk, $\mu \mathrm{g} / \mathrm{kg}$ & 0 & $<\mathrm{LOD}$ & - & - \\
\hline & & 25 & $28.35 \pm 3.79$ & 113.38 & 13.37 \\
\hline & & 50 & $40.59 \pm 5.26$ & 81.17 & 12.96 \\
\hline & & 100 & $89.93 \pm 8.96$ & 89.93 & 9.96 \\
\hline & $\begin{array}{l}\text { Meat, } \mu \mathrm{g} / \\
\mathrm{kg}\end{array}$ & 0 & $<L O D$ & - & - \\
\hline & & 75 & $74.45 \pm 13.37$ & 99.27 & 17.96 \\
\hline & & 150 & $150.72 \pm 20.36$ & 100.48 & 13.51 \\
\hline & & 300 & $234.66 \pm 34.52$ & 78.22 & 14.71 \\
\hline
\end{tabular}


$\mathrm{kg}$ in meat sample, the corresponding recoveries ranged from $81.63-108.00 \%, 87.44-110.13 \%$, and $77.83-97.52 \%$, respectively, with coefficients of variability (CVs) less than $12.16 \%$ (Table 2), indicating that the accuracy and precision of this ELISA meet the requirement of quantitative analysis. Compared to the previously reported ELISA methods (Additional file 1: Table S3), the assay sensitivity of this ELISA is much higher than that of Kitagawa et al. [25] and its assay accuracy is better than that of Suhren and Knappstein [15].

\section{LFIA}

The typical photo images of LFIA strip test are illustrated in Fig. 5. For semi-quantitative analysis, the standard curve was established using the relative optical density of the spiked and blank sample $\left(\mathrm{B} / \mathrm{B}_{0}\right)$ as the $\mathrm{Y}$ axis and the logarithmic concentration of colistin as the $\mathrm{X}$ axis (Fig. 5). The limit of detection (LOD) was set as the concentration of the analyte that leads to a $20 \%$ reduction in test line intensity as compared to blank sample. The LODs of colistin in phosphate buffer was calculated as $0.87 \mathrm{ng} / \mathrm{mL}$. By multiplying dilution factors, the LODs of colistin in swine feed, chicken feed, milk and meat were determined to be 110.4, $118.7,5.9$ and $23.9 \mu \mathrm{g} / \mathrm{kg}$, respectively, which were close to that of the developed ELISA method and were far below than the generally addition content of colistin $(\mathrm{mg} / \mathrm{kg}$ level) in animal feed [24] and the MRLs (50 or $150 \mu \mathrm{g} / \mathrm{kg}$ ) in animal-origin food [12]. To evaluate the capability of these LODs to distinguish negative and positive sample, various blank samples (four different samples for each matrix and three repeats for each sample) were subjected to the LFIA. It was indicated that the calculated detection values were all below the established LODs, demonstrating that these LODs would not result in false positive results (Table 2). Furthermore, the spiked recovery experiment was used to evaluate the LFIA accuracy and precision. As shown in Table 2, at the spiked concentration, the corresponding recoveries of colistin from animal feed, milk and meat samples ranged from $87.23-114.45 \%$, $81.17-113.38 \%$ and $78.22-100.48 \%$ respectively with CVs less than $18.26 \%$, demonstrating that the developed LFIA can be used as semi-quantitative analysis.

\section{Analysis of real samples}

To further validate the developed assays, twenty actual animal feed and food samples (six swine feed samples, six chicken feed samples, four milk samples and four meat samples) were collected from different farms and local markets and were analyzed by the developed ELISA, LFIA and LC-MS/MS methods. It should be noted that the feed samples were obtained from local market before the prohibited use of colistin in feed. As shown in Additional file 1: Table S4, fourteen samples including three swine feed samples, four chicken feed samples, four milk samples and three meat samples were determined as negative (Additional file 1: Table S4) by both the developed immunoassays and LC-MS/MS method. This result indicated the developed immunoassays did not produce false negative result. Six samples including three swine feed samples, two chicken feed samples and one meat sample were measured to contain colistin, and the detection values obtained by the developed ELISA and LFIA were consistent with that of LCMS/MS method (Fig. 6). These results demonstrated that the developed ELISA and LFIA could be used for the accurate determination of colistin in actual samples.

\section{Conclusion}

In the study, we developed a rapid one-step ci-ELISA and a LFIA for colistin in animal feed and food. The LODs of both methods are far below the generally addition content of colistin $(\mathrm{mg} / \mathrm{kg}$ level) in animal feed
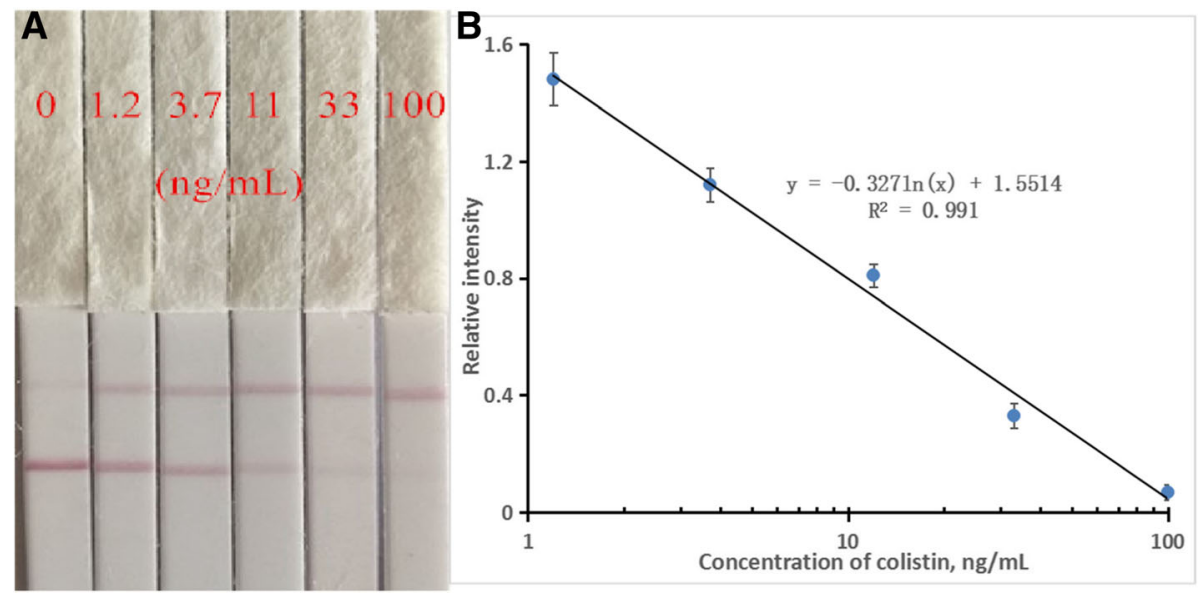

Fig. 5 Typical photo image (a) and calibration curve (b) of LFIA for different concentrations of colistin $(n=4)$ 


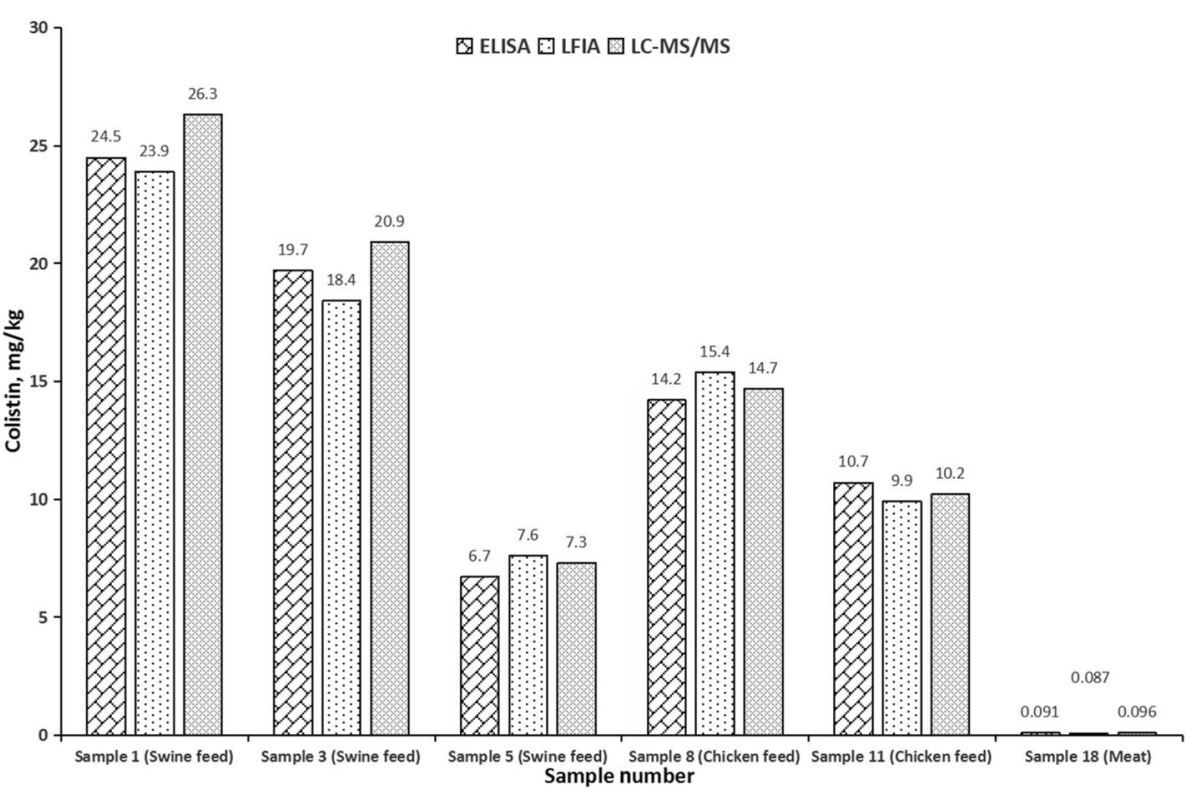

Fig. 6 Detection results of colistin in actual positive samples by ELISA, LFIA and HPLC method

and also meet the MRLs (50 or $150 \mu \mathrm{g} / \mathrm{kg}$ ) in animal-origin food set by authorities. Also, the recoveries of colistin from animal feed and food were within acceptable range with good assay precision. Furthermore, the analysis time of the one-step ci-ELISA was less than 60 min, and the analysis time of LFIA was less than $15 \mathrm{~min}$. Thus, these two immunoassays can be selectively used for rapidly monitoring the illegal use of colistin in animal feed and the colistin residue in animal-origin food.

\section{Additional file}

Additional file 1: Figure S1. Schemes of one-step indirect ELISA, two-step indirect ELISA and one-step direct ELISA for colistin. Figure S2. Ultraviolet-visible spectrum of four GNPs solutions synthesized by reducing chlorauric acid with 1.0, 1.6, 2.0 and $2.5 \mathrm{~mL}$ of citrate solution. Figure S3. TEM images of four GNPS solutions synthesized by reducing chlorauric acid with $1.0 \mathrm{~mL}$ (A), $1.6 \mathrm{~mL}$ (B), $2.0 \mathrm{~mL}$ (C) and $2.5 \mathrm{~mL}$ (D) of citrate solution. Table S1. The $\mathrm{IC}_{50}$ values of all sera from mice immunized with two different dosages. Table S2. Comparison of one step ci-ELISA, two step ci-ELISA and one step cd-ELISA regarding $I C_{50}$ values and assay time $(n=4)$. Table S3. Comparison of the developed ELISA method with that literature reported enzyme immunoassay. Table S4. Detection results of colistin in actual animal feed by ELISA, LFIA and HPLC method. (DOCX $723 \mathrm{~kb})$

\section{Abbreviations}

BSA: Bovine serum albumin; ci-ELISA: Competitive indirect ELISA: CVs: Coefficients of variability; EDC: 1-Ethyl-3-(3-dimethylaminopropyl) carbodiimide; ELISA: Enzyme-linked immunosorbent assay; FBS: Fetal bovine serum; FMOC-Cl: 9-Fluorenylmethyl chloroformate; GNP: Gold nanoparticle; HAT: Hypoxanthine-aminopterin-thymidine; HPLC: High performance liquid chromatography; HRP: Horseradish peroxidase; HT: Hypoxanthine-thymidine; $\mathrm{IC}_{50}$ : Half maximal inhibitory concentration; IgG: Immunoglobulin G; LC-MS/ MS: Liquid chromatography coupled with tandem mass spectrometry; LFIA: Lateral flow immunochromatographic assay; LOD: The limits of detection; mAb: Monoclonal antibody; MRLs: Maximum residue limits; OD: The optical density; OVA: Ovalbumin; PBS: Phosphate buffer saline; PEG 1500: Polyethylene glycol 1500; PEG: Polyethylene glycol; PVA: Polyvinyl alcohol; PVP: Polyvinyl pyrrolidone; TCA: Trichloroacetic acid aqueous solution; TEM: Transmission electron microscope; UV: Ultraviolet

\section{Acknowledgements}

The authors thank Beijing Advanced Innovation Center for Food Nutrition and Human Health and Chinese Universities Scientific Fund for financial support.

\section{Authors' contributions}

$J W, J Z$ and $X Z$ completed the majority of the experiments. YJ and XC participated in ELISA and LFIA analysis. DH and WL participated in data analysis and sample collection. LH participated in manuscript revision. YC designed the experiments and wrote the manuscript. All authors read and approved the final manuscript.

\section{Funding}

This work is financially supported by Beijing Advanced Innovation Center for Food Nutrition and Human Health and Basic Research Program of Science and Technology (2014FY111000)

\section{Availability of data and materials}

All data generated or analyzed during this study are included in this published article.

\section{Ethics approval}

The procedures of the animal experiment in this work were approved by the China Agricultural University Institutional Animal Care and Use Committee (CAll20160925-1, Beijing, China).

\section{Consent for publication}

Not applicable.

\section{Competing interests}

The authors declare that they have no competing interests.

\section{Author details}

${ }^{1}$ Beijing Advanced Innovation Center for Food Nutrition and Human Health, and State Key Laboratory of Animal Nutrition, College of Animal Science and 
Technology, China Agricultural University, Beijing, China. ${ }^{2}$ Department of Chemistry and Biochemistry, Florida State University, Tallahassee, FL, USA.

Received: 10 May 2019 Accepted: 9 August 2019

Published online: 17 October 2019

\section{References}

1. Rhouma M, Beaudry F, Letellier A. Resistance to colistin: what is the fate for this antibiotic in pig production? Int J Antimicrob Agents. 2016:48:119-26.

2. World Health Organization $(\mathrm{WHO})$. Critically important antimicrobials for human medicine: 3rd revision. 2011. http://apps.who.int/iris/bitstream/1 0665/77376/1/9789241504485_eng.pdf?ua=1\&ua=1. Accessed 10 May 2019.

3. Katsunuma $Y$, Hanazumi M, Fujisaki $H$, Minato $H$, Hashimoto $Y$, Yonemochi C. Associations between the use of antimicrobial agents for growth promotion and the occurrence of antimicrobial-resistant Escherichia coli and enterococci in the feces of livestock and livestock farmers in Japan. J Gen Appl Microbiol. 2007:53:273-9.

4. Bennett PM, Enne VI, Cassar C, Sprigings K, Woodward MJ. A high prevalence of antimicrobial resistant Escherichia coli isolated from pigs and a low prevalence of antimicrobial resistant $E$. coli from cattle and sheep in Great Britain at slaughter. FEMS Microbiol Lett. 2008;278:193-9.

5. Lu L, Dai L, Wang Y, Wu C, Chen X, et al. Characterization of antimicrobial resistance and integrons among Escherichia coli isolated from animal farms in eastern China. Acta Trop. 2010;113:20-5.

6. Rhouma M, Beaudry F, Thériault W, Letellier A. Colistin in pig production: chemistry, mechanism of antibacterial action, microbial resistance emergence, and one health perspectives. Front Microbiol. 2016;7(1789):1-22.

7. Liu YY, Wang Y, Walsh TR, Yi LX, Zhang R, Spencer J, et al. Emergence of plasmid-mediated colistin resistance mechanism MCR-1 in animals and human beings in China: a microbiological and molecular biological study. Lancet Infect Dis. 2016;16:161-8.

8. Walsh TR, Wu Y. China bans colistin as a feed additive for animals. Lancet Infect Dis. 2016;16:1102-3.

9. Shen Z, Wang Y, Shen Y, Shen J, Wu C. Early emergence of mcr-1 in Escherichia coli from food-producing animals. Lancet Infect Dis. 2016;16:293.

10. Chinese Ministry of Agriculture, Announcement No. 2428, July 26 of 2016. 2016. http://jiuban.moa.gov.cn/fwllm/zxbs/xzxk/spyj/201706/t201706 06_5662452.htm (In Chinese). Accessed 10 May 2019.

11. Bengtsson-palme J, Larsson D. Concentrations of antibiotics predicted to select for resistant bacteria: proposed limits for environmental regulation. Environ Int. 2016;86:140-9.

12. Codex Alimentarius. Maximum residue limits (MRLs) and risk management recommendations (RMRs) for residues of veterinary drugs in food drugs in foods. CAC/MRL 2-2017; 2017. p. 19-40.

13. Thomas AH, Thomas JM, Holloway I. Microbiological and chemical analysis of polymyxin B and polymyxin E (colistin) sulphates. Analyst. 1980;105:1068-75.

14. Leroy $P$, Decolin D, Nicolas S, Archimbault P, Nicolas A. Residue determination of two co-administered antibacterial agents - cephalexin and colistin - in calf tissues using high-performance liquid chromatography and microbiological methods. J Pharm Biomed Anal. 1989; 7:1837-46.

15. Suhren $G$, Knappstein K. Detection of colistin in spiked and incurred milk samples by LC- and ELISA-technique. Anal Chim Acta. 2005;529:97-101.

16. Li J, Milne RW, Nation RL, Turnidge JD, Coulthard K, Johnson DW. A simple method for the assay of colistin in human plasma, using pre-column derivatization with 9-fluorenylmethyl chloroformate in solid-phase extraction cartridges and reversed-phase high-performance liquid chromatography. J Chromatogr B Biomed Appl. 2001;761:167-75.

17. Cancho-Grande B, Rodríguez-Comesaña M, Simal-Gándara J. Simple HPLC determination of colistin in medicated feeds by pre-column derivatization and fluorescence detection. Chromatographia. 2001;54:481-4.

18. Morales-Muñoz S, de Castro MDL. Dynamic ultrasound-assisted extraction of colistin from feeds with on-line pre-column derivatization and liquid chromatography-fluorimetric detection. J Chromatogr A. 2005;1066:1-7.

19. Chepyala D, Tsai IL, Sun HY, Lin SW, Kuo CH. Development and validation of a high-performance liquid chromatography-fluorescence detection method for the accurate quantification of colistin in human plasma. J Chromatogr B. 2015:980:48-54

20. Dotsikas Y, Markopoulou CK, Koundourellis JE, Loukas YL. Validation of a novel LC-MS/MS method for the quantitation of colistin a and B in human plasma. J Sep Sci. 2011;34:37-45.
21. Jansson B, Karvanen M, Cars O, Plachouras D, Friberg LE. Quantitative analysis of colistin a and colistin B in plasma and culture medium using a simple precipitation step followed by LC/MS/MS. J Pharm Biomed Anal. 2009:49:760-7.

22. Mercier T, Tissot F, Gardiol C, Corti N, Wehrli S, Guidi M, et al. Highthroughput hydrophilic interaction chromatography coupled to tandem mass spectrometry for the optimized quantification of the anti-gramnegatives antibiotic colistin a/B and its pro-drug colistimethate. J Chromatogr A. 2014;1369:52-63.

23. Zhao M, Wu XJ, Fan YX, Guo BN, Zhang J. Development and validation of a UHPLC-MS/MS assay for colistin methanesulphonate (CMS) and colistin in human plasma and urine using weak-cation exchange solid-phase extraction. J Pharm Biomed Anal. 2016;124:303-8.

24. Fu Q, Li X, Zheng K, Ke Y, Wang Y, Wang L, et al. Determination of colistin in animal tissues, egg, milk, and feed by ultra-high performance liquid chromatography-tandem mass spectrometry. Food Chem. 2018;248:166-72.

25. Kitagawa T, Ohtani W, Maeno Y, Fujiwara K, Kimura Y. Sensitive enzyme immunoassay of colistin and its application to detect residual colistin in rainbow trout tissue. J Assoc Off Anal Chem. 1985;68:661-4.

26. Campbell K, Fodey T, Flint J, Danks C, Danaher M, O'Keeffe M, et al. Development and validation of a lateral flow device for the detection of nicarbazin contamination in poultry feeds. J Agric Food Chem. 2007;55: 2497-503.

27. Gobin P, Lemaître F, Marchand S, Couet W, Olivier J-C. Assay of colistin and colistin methanesulfonate in plasma and urine by liquid chromatographytandem mass spectrometry. Antimicrob Agents Chemother. 2010;54:1941-8.

28. Xu Y, Tian X, Ren C, Huang H, Zhang X, Gong X, et al. Analysis of colistin a and $B$ in fishery products by ultra performance liquid chromatography with positive electrospray ionization tandem mass spectrometry. J Chromatogr B. 2012;899:14-20.

29. Chen Y, Wang Z, Wang Z, Tang S, Zhu Y, Xiao X. Rapid enzyme-linked immunosorbent assay and colloidal gold immunoassay for kanamycin and tobramycin in swine tissues. J Agric Food Chem. 2008;56:2944-52.

30. Song C, Liu Q, Zhi A, Yang J, Zhi Y, Li Q, et al. Development of a lateral flow colloidal gold immunoassay strip for the rapid detection of olaquindox residues. J Agric Food Chem. 2011;59:9319-26.

31. Goodrow MH, Harrison RO, Hammock BD. Hapten synthesis, antibody development, and competitive inhibition enzyme immunoassay for striazine herbicides. J Agric Food Chem. 1990;38:990-6.

32. Liu BH, Tsao ZJ, Wang JJ, Yu FY. Development of a monoclonal antibody against ochratoxin a and its application in enzyme-linked immunosorbent assay and gold nanoparticle immunochromatographic strip. Anal Chem. 2008:80:7029-35.

33. Anfossi L, Giovannoli C, Giraudi G, Biagioli F, Passini C, Baggiani C. A lateral flow immunoassay for the rapid detection of ochratoxin $a$ in wine and grape must. J Agric Food Chem. 2012;60:11491-7.

34. U.S. Food and Drug Administration, Q2B validation of analytical procedures: methodology, Guidance for Industry, November of 1996. 1996. https://www. fda.gov/downloads/drugs/guidances/ucm073384.pdf. Accessed 10 May 2019.

\section{Ready to submit your research? Choose BMC and benefit from:}

- fast, convenient online submission

- thorough peer review by experienced researchers in your field

- rapid publication on acceptance

- support for research data, including large and complex data types

- gold Open Access which fosters wider collaboration and increased citations

- maximum visibility for your research: over $100 \mathrm{M}$ website views per year

At $\mathrm{BMC}$, research is always in progress.

Learn more biomedcentral.com/submission 